\title{
Comparison of intrinsic capacity factors in older individuals before and during COVID-19 in the context of healthy ageing in Baltic Countries
}

\author{
Madara Mikelsone ${ }^{1, *}$, Ieva Reine $^{1}$, Diana Baltmane $^{1}$, Andrejs Ivanovs ${ }^{1}$, and Signe Tomsone ${ }^{2}$ \\ ${ }^{1}$ Riga Stradins University, Statistics Unit, Riga, Latvia \\ ${ }^{2}$ Riga Stradins University, Department of Rehabilitation, Riga, Latvia
}

\begin{abstract}
The COVID-19 in the context of healthy ageing is associated with decline in body functional abilities and serious illness in older individuals. Regular assessment of ageing processes, including intrinsic capacity factors, provides an opportunity for better understanding of the individual's functional abilities and vulnerabilities. Based on the data (2017-2020) from two waves (7 and 8) of the Survey of Health, Ageing and Retirement in Europe (SHARE), an evaluation and comparison of the intrinsic capacity factors of older individuals (50+ years) before and during COVID-19 was conducted, including data from 4422 individuals in Baltic countries (from Latvia - 648, Lithuania 1079 and Estonia - 2695). Excellent or very good health status before the outbreak reported $35.3 \%$ respondents in Latvia, $54.9 \%$ in Lithuania and $45.3 \%$ in Estonia $(\mathrm{p}<0.001)$. On worsened health status since the outbreak reported $7 \%$ respondents in Latvia, $13.8 \%$ in Lithuania and $5.9 \%$ in Estonia $(p<0.001)$. Feeling of nervousness, depression and loneliness during COVID-19 outbreak increased among all respondents, regardless of nationality and severity of symptoms before outbreak $(p<0.001)$. The results indicate that during COVID-19 outbreak respondents were experiencing deterioration in cognitive and psychological health. To maintain the level of individual's functional abilities during situations like COVID-19 outbreak preventive actions are needed by promoting physical activities and social networks, especially for older individuals.
\end{abstract}

\section{Introduction}

Since 2015, the World Health Organization (WHO) has developed Healthy Ageing Strategy, which defines healthy ageing as the process of developing and maintaining the functional ability that enables wellbeing in older age [1].

An individual's intrinsic capacity is a powerful predictor of the future ageing process and includes 5 factors- cognitive, psychological, sensory, locomotion and vitality. Exploration of them can provide necessary information to better understand the individual's functional abilities and vulnerabilities during outbreak of COVID-19, as each of them interacts closely with the others as part of a dynamic interconnected environment (see Fig. 1) [2-4].

\footnotetext{
*Corresponding author: madara.mikelsone@rsu.lv
} 


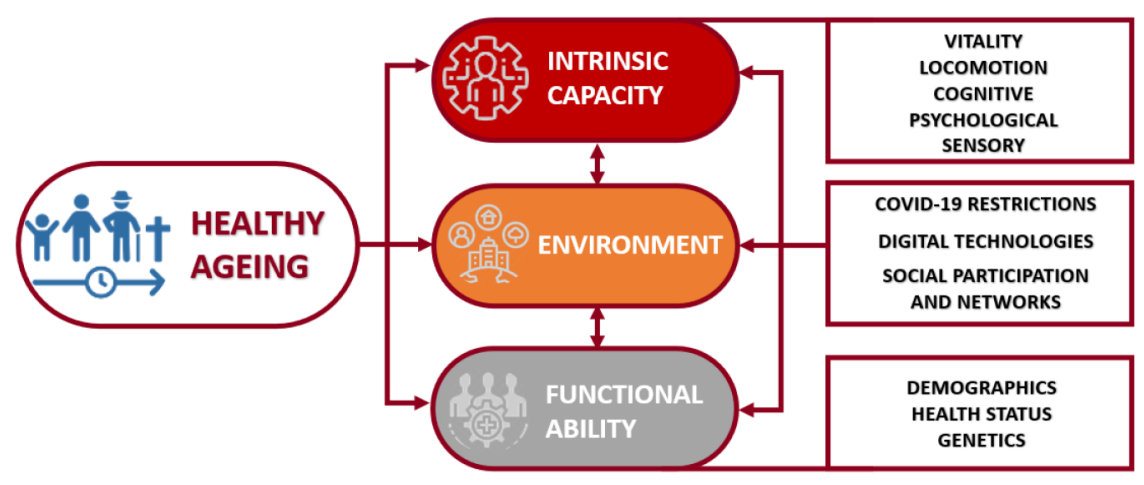

Figure 1. Determinants of healthy ageing (author's interpretation) [2].

COVID-19 outbreak threatens each of those factors, especially in older adults by compromising short-term and long-term outcomes, thereby negatively impacting health and wellbeing.

Early impact of the COVID-19 outbreak can be associated with such intrinsic capacity factors as vitality (health status), locomotion (mobility, functional abilities, physical activities), cognitive and psychological (depression, anxiety, nervousness, suicidal feelings, low satisfaction with life etc.) [5-7].

National level public health restrictions due to COVID-19 outbreak (lockdown, social distancing, etc.) have significantly changed the environment in which older individuals live. Social participation can be considered as a stimulus to increase the level of physical activities and cognitive functions. Less or no social interaction has negative impact on cognitive, psychological and physical functions in older individuals, especially for those, who require regular assistance in daily tasks and constant help to meet their needs, as well as their relatives, who are their main caregivers $[8,9]$.

Due to COVID-19 restrictions, the access to various public services (social and entertainment facilities, healthcare, shops etc.) has been noticeably reduced and the internet and other digital technologies have played a large role by enabling those services as well as connections with family, friends and community, however, older individuals lack necessary skills to fully exploit them.

In order to implement the necessary measures for reducing and preventing the consequences of the COVID-19 pandemic, the information on the current ageing status as well as comparison in long-term is needed.

The aim of the study was to evaluate and compare intrinsic capacity factors of older individuals before and during COVID-19 outbreak in three Baltic countries.

\section{Material and methods}

Based on the data (2017-2020) from two waves (7 and 8) of the Survey of Health, Ageing and Retirement in Europe (SHARE) ${ }^{1}$, an evaluation and comparison of the intrinsic capacity factors of older individuals before and during COVID-19 outbreak was conducted.

\footnotetext{
${ }^{1}$ This paper uses data from SHARE Wave 7 (DOI: 10.6103/SHARE.w7.711)and Wave 8 (DOI: 10.6103/SHARE.w8cabeta.001), see Börsch-Supan et al. (2013) for methodological details. The SHARE data collection has been funded by the European Commission.
} 
Respondents who participated in the longitudinal survey with computer-assisted personal interviewing (CAPI), computer assisted telephone interview (CATI) and were at least 50 years old were selected for the research. Sample consisted of 4422 respondents from Latvia $(n=648)$, Estonia $(n=2695)$ and Lithuania $(n=1079)$.

In order to ensure the representativeness of the data, weighing procedure for data was performed using calibrated (cross-sectional) individual weight - CAPI and CATI interviews. They were computed separately by country to match the size of national target populations of individuals across eight gender-age groups (i.e., males and females in the age classes "5059", "60-69", "70-79", "80+" and across NUTS-1 (major socio-economic regions) [10].

Descriptive statistics as well as inferential statistics (Chi-square test, univariate binary logistic regression) were used to analyse the results. Based on a large sample size, in order to evaluate statistically significant result for Chi-square test, strength of association (Cramer's V) was provided. $P<0.05$ was set as the significance level.

\section{Results}

Based on the data from SHARE Wave 8, the main demographic results indicated that $50.7 \%$ of SHARE respondents from Latvia, $42.0 \%$ from Lithuania and $51.9 \%$ from Estonia were divorced, widowed or have never been married. No children were reported by $51.8 \%$ of respondents from Latvia, $49.1 \%$ from Lithuania and $42.3 \%$ from Estonia. One or both living parents were reported by $15.8 \%$ of respondents from Latvia, $15.1 \%$ from Estonia and $12.5 \%$ from Lithuania. Health status of one or both living parents as poor/fair was reported by almost all respondents (Latvia-99.3\%, Lithuania-92.0\%, Estonia-98.0\%).

\subsection{Vitality}

In 2017 poor or fair self-rated health status was reported by $65.4 \%$ respondents from Latvia, 57.9\% from Lithuania and $67.5 \%$ from Estonia ( $p<0.001$, Cramer's $V=0.087$ ). In 2018/2019 the proportion of those respondents increased in Latvia (71.3\%) and decreased in Estonia (66.2\%) and Lithuania (54.4\%) $(p<0.001$, Cramer's $V=0.157)$.

During COVID-19 outbreak worsened health status was reported by $7.0 \%$ respondents from Latvia, 13.8\% from Lithuania and 5.9\% from Estonia ( $p<0.001$, Cramer's $V=0.086$ ). From all those respondents, who rated their health as poor or fair before COVID-19 outbreak, worsened health status during outbreak was reported by $8.5 \%$ of respondents from Latvia, $21.9 \%$ from Lithuania and $28.3 \%$ from Estonia.

Diagnosed with major condition since outbreak was reported by $7.2 \%$ respondents from Latvia, 7.0\% respondents from Lithuania and 6.9\% respondents from Estonia. The obtained results indicate a relatively similar tendency in all age groups, however, in Latvia a smaller proportion of respondents in the age group "50-59 years" (15.8\%) were diagnosed with a major condition since outbreak, compared to Lithuania (27.8\%) and Estonia (34.1\%). It was found that a relatively small proportion of respondents with no co-morbidities before COVID-19 outbreak, i.e., $4.7 \%$ of respondents from Latvia, $2.9 \%$ from Lithuania and 3.7\% from Estonia during COVID-19 outbreak were diagnosed with a major condition. Most common diseases were high blood pressure or hypertension (Latvia- 52.6\%, Lithuania- $33.6 \%$, Estonia-33.7\%), heart attack or other heart problems (Latvia- 41.9\%, Lithuania- 29.9\%, Estonia- 25.7\%), diabetes or high blood sugar (Latvia- 11.3\%, Lithuania- 9.4\%, Estonia$11.5 \%)$. 


\subsection{Locomotion}

Results associated with locomotion (mobility, physical activities) are provided in Table 1.

Table 1. Locomotion factors before and during COVID-19 outbreak.

\begin{tabular}{|c|c|c|c|c|}
\hline $\begin{array}{l}\text { Before COVID-19 outbreak } \\
(2018 / 2019) \\
\end{array}$ & Latvia & Estonia & Lithuania & $\begin{array}{c}P \text { value/ } \\
\text { Cramer's } V\end{array}$ \\
\hline Age prevents from doing things & $57.6 \%$ & $53.9 \%$ & $66.0 \%$ & $<0.001 / 0.105$ \\
\hline $\begin{array}{l}\text { Limited in activities because of } \\
\text { health }\end{array}$ & $59.7 \%$ & $58.5 \%$ & $48.1 \%$ & $<0.001 / 0.112$ \\
\hline Difficulties in daily tasks & $54.2 \%$ & $51.1 \%$ & $51.6 \%$ & $<0.001 / 0.021$ \\
\hline Difficulties in personal needs & $20.5 \%$ & $25.5 \%$ & $20.0 \%$ & $<0.001 / 0.053$ \\
\hline $\begin{array}{l}\text { Daily activities that are vigorous } \\
\text { once a week or more }\end{array}$ & $60.4 \%$ & $46.0 \%$ & $46.8 \%$ & $<0.001 / 0.103$ \\
\hline $\begin{array}{l}\text { Daily activities requiring moder- } \\
\text { ate level of energy once a week or } \\
\text { more }\end{array}$ & $80.5 \%$ & $81.3 \%$ & $79.1 \%$ & $<0.001 / 0.079$ \\
\hline Gone to a sport or other club: & $5.2 \%$ & $22.1 \%$ & $7.7 \%$ & $<0.001 / 0.154$ \\
\hline from them - almost every day & $0.0 \%$ & $8.4 \%$ & $10.6 \%$ & $<0.001 / 0.130$ \\
\hline DuringCOVID-19 outbreak & Latvia & Estonia & Lithuania & $\begin{array}{c}P \text { value/ } \\
\text { Cramer's } V\end{array}$ \\
\hline Gone for a walk less often or never & $38.5 \%$ & $32.9 \%$ & $52.8 \%$ & $<0.001 / 0.171$ \\
\hline Never left home since outbreak & $14.1 \%$ & $17.8 \%$ & $17.6 \%$ & $<0.001 / 0.045$ \\
\hline Went shopping less often or never & $63.2 \%$ & $68.8 \%$ & $78.3 \%$ & $<0.001 / 0.118$ \\
\hline
\end{tabular}

Of those respondents who noted limited daily activities because of age, $75.3 \%$ from Latvia, $56.7 \%$ from Lithuania and $69.2 \%$ from Estonia also have limited daily activities because of health.

Of those respondents who noted difficulties in daily tasks, $37.5 \%$ from Latvia, $34.4 \%$ from Lithuania and $44.5 \%$ from Estonia need regular assistance in managing those tasks.

Of the respondents who noted difficulties in personal needs, $50.0 \%$ from Latvia, $49.5 \%$ from Lithuania and $65.6 \%$ from Estonia needed regular assistance in managing those needs.

Evaluating the association between difficulties in daily tasks and personal needs, $36.6 \%$ of respondents from Latvia, 39.2\% from Lithuania and 46.8\% from Estonia noted both difficulties.

Of those respondents who participated in daily activities requiring moderate level of energy once a week or more, $21.2 \%$ from Latvia, $29.9 \%$ from Lithuania and $28.8 \%$ from Estonia never left home during COVID-19 outbreak, while $32.6 \%$ of respondents from Latvia, $34.7 \%$ from Lithuania and $23.8 \%$ from Estonia never went for a walk since outbreak.

\subsection{Cognitive and psychological status}

Results associated with cognitive and psychological status are provided in Table 2.

The results indicate that during COVID-19 outbreak, not only those respondents, who already had those symptoms before the outbreak, experienced increased intensity of depression, but also those respondents, who never had such symptoms before (Latvia- 32.0\%, Lithuania- $61.7 \%$, Estonia- $63.5 \%$ ). Similar tendency was found also with increased intensity of loneliness, which during COVID-19 outbreak experienced not only those respondents, 
Table 2. Comparison of cognitive and psychological status before and during COVID-19 outbreak.

\begin{tabular}{lcccc}
\hline $\begin{array}{l}\text { Before COVID-19 outbreak } \\
\mathbf{( 2 0 1 8 / 2 0 1 9 )}\end{array}$ & Latvia & Estonia & Lithuania & $\begin{array}{c}\boldsymbol{P} \text { value/ } \\
\text { Cramer's } \boldsymbol{V}\end{array}$ \\
\hline Sad or depressed & $45.0 \%$ & $46.7 \%$ & $45.0 \%$ & $<0.001 / 0.014$ \\
\hline Lonely (often or some of the time) & $45.0 \%$ & $27.1 \%$ & $26.6 \%$ & $<0.001 / 0.122$ \\
\hline Felt nervous last month & $30.8 \%$ & $27.6 \%$ & $34.7 \%$ & $<0.001 / 0.060$ \\
\hline During COVID-19 outbreak & Latvia & Estonia & Lithuania & $\begin{array}{c}\boldsymbol{P} \text { value/ } \\
\text { Cramer's } \boldsymbol{V}\end{array}$ \\
\hline Increased intensity of depression & $46.0 \%$ & $61.9 \%$ & $61.0 \%$ & $<0.001 / 0.106$ \\
\hline Increased intensity of loneliness & $16.1 \%$ & $21.3 \%$ & $25.8 \%$ & $<0.001 / 0.090$ \\
\hline Increased intensity of nervousness & $68.5 \%$ & $72.3 \%$ & $75.7 \%$ & $<0.001 / 0.057$ \\
\hline
\end{tabular}

who already had those symptoms before the outbreak, but also those respondents, who never or rarely had such symptoms before (Latvia-13.7\%, Lithuania-21.1\%, Estonia-18.7\%).

No significant associations were found between increased intensity of depression during COVID-19 outbreak and demographics, vitality and locomotion factors, regardless of nationality, except that all respondents from Latvia with no education experienced increased intensity of depression during COVID-19 outbreak, if compared to Lithuania (49.8\%) and Estonia (44.1\%).

No significant associations were found between increased intensity of loneliness during COVID-19 outbreak and demographic or locomotion factors, regardless of nationality. However, results indicate that the respondents, who rated their health as poor or fair before outbreak, are more likely to experience increased intensity of loneliness during the outbreak (Latvia - OR 2.43 (95\%CI 2.36-2.49), Lithuania - OR 5.03 (95\%CI 4.94-5.12), Estonia OR 2.41 (95\%CI 2.32-2.49). The same refers to those respondents who were diagnosed with major condition since outbreak (Latvia - OR 1.78 (95\%CI 1.73-1.83), Lithuania - OR 1.30 (95\%CI 1.26-1.34), Estonia- OR 1.57 (95\%CI 1.51-1.63)).

Assessing the relationship between nervousness and increased feeling of depression during the outbreak of COVID-19, the results indicate that of those respondents whose intensity of nervousness increased during the outbreak, $65.4 \%$ of respondents from Latvia, $81.6 \%$ from Lithuania and $89.2 \%$ from Estonia also experienced increased intensity of depression.

Assessing the relationship between nervousness and increased feeling of loneliness during the outbreak of COVID-19, the results indicate that of those respondents whose intensity of nervousness increased during the outbreak, $39.3 \%$ of respondents from Latvia, $49.8 \%$ from Lithuania and $39.5 \%$ from Estonia also experienced increased intensity of loneliness.

\subsection{Social networks}

Results associated with social networks are provided in Table 3.

Of all respondents who indicated social contacts with children less often or never during COVID-19 outbreak, 66.7\% from Latvia, 74.4\% from Lithuania and 65.6\% from Estonia noted electronic contact frequency daily or several times a week.

Of all respondents who indicated less or no social contact with children, $23.0 \%$ of respondents from Latvia, 13.2\% from Lithuania and 9.7\% from Estonia before theCOVID-19 outbreak received assistance from children in meeting daily needs. Also, of these respondents, $64.7 \%$ from Latvia, $48.8 \%$ from Lithuania and 57.3\% from Estonia reported limited activities because of health, while $56.6 \%$ from Latvia, $68.2 \%$ from Lithuania and $54.5 \%$ of Estonia reported limited daily activities because of age. 
Table 3. Social networks before and during COVID-19 outbreak.

\begin{tabular}{lllll}
\hline $\begin{array}{l}\text { Before COVID-19 outbreak } \\
\mathbf{( 2 0 1 8 / 2 0 1 9 )}\end{array}$ & Latvia & Estonia & Lithuania & $\begin{array}{c}\boldsymbol{P} \text { value/ } \\
\text { Cramer's } \boldsymbol{V}\end{array}$ \\
\hline Personal contact with children daily & $41.2 \%$ & $43.3 \%$ & $53.1 \%$ & $<0.001 / 0.132$ \\
\hline $\begin{array}{l}\text { Personal contact with one or both par- } \\
\text { ents daily/ several times a week }\end{array}$ & $68.8 \%$ & $54.5 \%$ & $78.7 \%$ & $<0.001 / 0.190$ \\
\hline \hline During COVID-19 outbreak & Latvia & Estonia & Lithuania & $\begin{array}{c}\boldsymbol{P} \text { value/ } \\
\text { Cramer's } \boldsymbol{V}\end{array}$ \\
\hline $\begin{array}{l}\text { Social contact with children less often } \\
\text { or never }\end{array}$ & $52.2 \%$ & $46.7 \%$ & $62.1 \%$ & $<0.001 / 0.115$ \\
\hline $\begin{array}{l}\text { Social contact with parents less often } \\
\text { or never }\end{array}$ & $66.2 \%$ & $37.5 \%$ & $70.1 \%$ & $<0.001 / 0.040$ \\
\hline $\begin{array}{l}\text { Social contact with relatives less often } \\
\text { or never }\end{array}$ & $86.9 \%$ & $87.8 \%$ & $93.4 \%$ & $<0.001 / 0.103$ \\
\hline $\begin{array}{l}\text { Social contact with friends, neigh- } \\
\text { bours, colleagues less often or never }\end{array}$ & $67.5 \%$ & $59.5 \%$ & $74.4 \%$ & $<0.001 / 0.126$ \\
\hline
\end{tabular}

Of all respondents who indicated social contacts with parents less often or never during COVID-19 outbreak, only 28.5\% from Latvia, 54.9\% from Lithuania and $41.7 \%$ from Estonia noted electronic contact frequency daily or several times a week.

Respondents who indicated less or no social contact with parents during COVID-19 outbreak are more likely to experience increased intensity of loneliness, it was observed only in Estonia (OR 2.04, 95\% CI (1.87-2.22)) and depression in Estonia (OR2.55 (95\%CI 2.412.69)) and Lithuania (OR 3.84 (95\%CI 3.72-3.97)).

Respondents who indicated less or no social contact with relatives during COVID-19 outbreak are more likely to experience increased intensity of depression in Latvia (OR 4.89 (95\%CI 4.65-5.14)) and Lithuania (OR 3.22 (95\%CI 3.13-3.30)) and loneliness in Latvia (OR 2.51 (95\%CI 2.41-2.61)), Lithuania (OR 2.27 (95\%CI 2.19-2.35)) and Estonia (OR 2.20 (95\% CI 2.08-2.32)).

Of all those respondents who indicated social contacts with relatives less often or never during COVID-19 outbreak, only 26.6\% from Latvia, 32.6\% from Lithuania and 29.3\% from Estonia noted electronic contact frequency daily or several times a week.

Of all those respondents who indicated social contacts with friends, neighbours, colleagues etc. less often or never during COVID-19 outbreak, only 17.1\% from Latvia, 36.1\% from Lithuania and $33.8 \%$ from Estonia noted electronic contact frequency daily or several times a week.

\section{Discussion}

Long-term evaluation of the ageing process indicates slightly increased proportion of respondents with worsened health status before and duringCOVID-19 outbreak, as well as limited daily activities because of health and age. These changes can be explained by the ageing process of individuals and currently the proportion of those respondents is not growing rapidly. Older individuals, regardless of nationality, already show signs of physical inactivity and since COVID-19 outbreak has become even much less active, which can be explained with national level safety measures to reduce the spread of COVID-19. However, in the future this might lead to more rapid proportional increase of respondents with worsened health status, 
limitations in daily activities, and with necessity for regular assistance in managing everyday tasks.

During COVID-19 outbreak, older individuals experienced increased intensity of depression, loneliness and nervousness, but presence of such symptoms was already observed before the COVID-19 outbreak.

During COVID-19 outbreak social contacts with children, parents, relatives, as well as neighbours, friends, colleagues, etc. has decreased or completely stopped because of national level public health restrictions, but at the same time electronic communication with children has become more frequent, even for those respondents, who had less or no social contact with children before the outbreak.

Obtained results as well as various similar studies indicate findings in associations between social network and cognitive functions [11-13] - increased intensity of depression and loneliness as the result of lack of social contacts, especially with parents and relatives.

The results of a study conducted in China [6] indicate of association between increased intensity of loneliness and depression and such demographic factors as age, marital status (divorced or widowed), lower level of education and lower level of income, while the present study did not show such associations, with one exception. Namely, all respondents in Latvia with no obtained education experienced increased intensity of depression during the outbreak.

WHO recommendation for maintaining cognitive and physical health during COVID-19 is the use of digital technologies (for communication, online workout etc.) in everyday life, bet results indicate that more than a half of respondents in Latvia (74.0\%) and Lithuania $(68.3 \%)$ lack necessary skills to fully exploit them.

Further longitudinal research is needed as exploration of changes associated with intrinsic capacity factors, especially during COVID-19 pandemics can provide necessary information for preventive actions in order to reduce the early and long-term impact of situations like COVID-19 pandemics to ageing process as well as to maintain their current functional abilities of older individuals as long as possible.

The study was performed within the project "Impact of Covid-19 on ageing populations in Latvia: recommendations for mitigation health and social effects and preparedness for potential crises in the future" in the framework of VPP-COVID-2020/1-0011 "Impact of COVID-19 on health care system and public health in Latvia; ways in preparing health sector for future epidemics".

\section{References}

[1] "Ageing: Healthy ageing and functional ability" (WHO, 2020)

[2] M. Cesari, I. Araujo de Carvalho, J. Thiyagarajan, C. Cooper, F. Martin, J. Reginster et al. Gerontol A Biol Sci Med Sci 73 (2018)

[3] T. Nestola, L. Orlandini, J.R. Beard, M. Cesari. J Nutr Health Aging 24 (2020)

[4] T. Cosco, B. Stephan, C. Brayne. International Psychogeriatrics 27 (2015)

[5] Z.H.Wang, S.G. Qi, P.X. Mao, Y.L. He, J. Li, S.Y. Xiao, H.M. Peng, W.W. Sun, H.Y. Guo, M. Liu. Zhonghua Yi Xue Za Zhi. 100 (2020)

[6] W. Ping, J. Zheng, X. Nju, C. Guo, J. Zhang, Y. Shi. PLoS One. 15 (2020)

[7] J.A. Thiyagarajan, I. Araujo de Carvalho, J.P. Peña-Rosas, S. Chadha, S.P. Mariotti, T. Dua. (Redesigning care for older people to preserve physical and mental capacity: WHO guidelines on community-level interventions in integrated care, 2019)

[8] L. Goethals, N. Barth, J. Guyot, D. Hupin, T. Celarier, B. Bongue. JMIR Aging 3 (2020)

[9] K.L. Fingerman, M. Huo, S.T. Charles, D.J. Umberson. J Gerontol B Psychol Sci Soc Sci 75 (2020) 
[10] M. Bergmann, A. Scherpenzeel \& A. Börsch-Supan (SHARE Wave 7 Methodology: Panel innovations and life histories. Munich: MEA, Max Planck Institute for Social Law and Social Policy 2019)

[11] Y.S. Bergman, D. Segel-Karpas. J Affect Disord. 214 (2018)

[12] L.C. Hawkley, J.T. Cacioppo. Annals of Behavioral Medicine. 42 (2010)

[13] W. Sepúlveda-Loyola, I. Rodriguez-Sánchez, P. Pérez-Rodriguez, F. Ganz, R. Torralba, D.V. Oliveira, L. Rodriguez-Mañas. The Journal of Nutrition, Health \& Aging (2020) 